\title{
Management of a Recurrent Pyogenic Granuloma of the Hard Palate with Diode Laser: A Case Report
}

\author{
Güzin Neda Hasanoglu Erbasar ${ }^{1 *}$, Burcu Senguven², Sibel Elif Gultekin ${ }^{2}$, Sedat Cetiner ${ }^{3}$ \\ 1Private Practice, Ankara, Turkey \\ ${ }^{2}$ Gazi University, School of Dentistry, Department of Oral Pathology, Ankara, Turkey \\ ${ }^{3}$ Gazi University, School of Dentistry, Department of Oral Surgery, Ankara, Turkey
}

\author{
*Correspondence to \\ Güzin Neda Hasanoglu Erbasar \\ DDS, PhD; Private Practice, \\ Karanfil Sokak No:11/9 Kızılay, \\ Ankara, Turkey. \\ Tel: +90-5555266751; \\ Fax: +90-3124196969 \\ Email :neda986@gmail.com
}

Published online 7 January 2016

\begin{abstract}
Introduction: Pyogenic granuloma (PG) is a prevalent inflammatory hyperplasia of skin and oral mucosa which is often caused by constant low-grade local irritation, traumatic injury or hormonal factors. In many cases, gingival irritation and inflammation due to poor oral hygiene are precipitating factors. Oral PG occurs predominantly on the gingiva, but it is also encountered on the lips, tongue, buccal mucosa and rarely on the hard palate. Although surgical excision is the first choice of treatment, many other treatment modalities could be counted such as cryosurgery, sodium tetradecyl sulfate sclerotherapy, intralesional steroids, flash lamp pulsed dye laser, neodymium-doped yttrium aluminium garnet (Nd:YAG) laser, carbon dioxide (CO2) laser, erbium-doped yttrium aluminum garnet (Er:YAG) lasers and diode laser have been suggested. After surgical excision recurrence occurs up to $16 \%$ of these lesions. It is believed that recurrence ensues as a result of incomplete excision, failure to eliminate etiologic factors or repeated trauma.

Case Report: A 50-year-old female was referred to the Department of Oral Surgery, Gazi University, School of Dentistry, complaining of a swelling and growth on the right side of the hard palate for four months. Patient reported a similar growth in the same area about two years earlier, which had turned out to be a PG by histopathology. The treatment plan included surgical excision of the lesion using diode laser.

Results: The patient reported no pain after the surgery. She was discharged with a prescription of chlorhexidine mouthwash and necessary post-operative instructions. At 7 days follow up visit, immediate recurrence of the lesion was observed, and it was excised by diode laser with $2 \mathrm{~mm}$ margins at its clinical periphery, to a depth up to the periosteum, by the same operator. No recurrence or scarring was observed in 14 months follow-up.

Conclusion: Although diode laser is a secure and efficient technique for the treatment of intraoral PG, in order to minimize its recurrence, the lesion should be excised with a wider margin down to the periosteum or to the causing agent. Also due to its high recurrence rate, long-term follow-up is recommended.

Keywords: Pyogenic Granuloma; Recurrence; Diode laser.
\end{abstract}

\section{Introduction}

Pyogenic granuloma (PG) is a prevalent, benign mucocutaneous lesion exhibited by an exuberant tissue, caused by a local irritation or trauma. ${ }^{1-3}$ It was first described in English literature by Hullihen ${ }^{4}$ in 1844 ; but the term 'pyogenic granuloma' or 'granuloma pyogenicum' was presented by Hartzell ${ }^{5}$ in 1904 . However, the term 'pyogenic granuloma' can be a misnomer because the lesion neither causes pus formation nor it represents a true granuloma, histologically. Some researchers use the term "lobular capillary hemangioma" which is histologically a more accurate term for this lesion. ${ }^{2,6,7}$

Clinically, PG appears as a sessile or pedunculated exophytic mass with smooth or lobulated surface that may easily bleed or ulcerate, and covered by yellow fibrinous membrane. The color of the lesion depends on the vascularity of the growth, so it can be red, purple or pink. . $^{1,3,8-10}$ In the $75 \%$ of all cases, gingiva is the most affected site by PG. Aside from the gingiva it is also encountered on the lips, tongue, buccal mucosa and the hard palate. The maxillary gingiva is more commonly affected than the mandibular one and the anterior region more than the posterior. Also the lesions are more frequently on the buccal side of the gingiva than the lingual side. , $^{6,10,11}$

The lesion usually develops slowly, without pain and asymptomatically. But in some cases it may develops fast, reaches its full size and remains stable. The size ranges from a few millimeters to several centimeters but it rarely

Please cite this article as follows: Hasanoglu Erbasar GN, Senguven B, Gultekin SE, Cetiner S. Management of a recurrent pyogenic granuloma of the hard palate with diode laser: a case report. J Lasers Med Sci. 2016;7(1):56-61. doi:10.15171/jlms.2016.12. 
exceeds $2 \mathrm{~cm}$. PG can be seen at any age, but more often between 10 and 40, the peak appears during the second decade of life. It is also more frequent in young adult females, probably due to the vascularization effects of estrogen and progesterone. ${ }^{1,69-11}$

Most of the time, a known stimulant or injury such as calculus or foreign material in the gingival crevice pave the way for the occurrence of PG, and the irritation of the fibro-vascular connective tissue results in exuberant proliferation of a granulation tissue. ${ }^{12,13}$ Other factors that could cause PG are some hormones, certain kinds of drugs (e.g. oral contraceptives, isotretinoin), bacteria and viruses. ${ }^{1,10,14}$ Also deciduous teeth injury, ${ }^{15}$ aberrant tooth development ${ }^{16}$ and even teeth eruption, ${ }^{17}$ have been considered as predisposing factors for PG development.

Differential diagnosis of PG comprises peripheral giant cell granuloma, peripheral ossifying fibroma, peripheral odontogenic fibroma, hemangioma, hyperplastic gingival inflammation, conventional granulation tissue, Kaposi's sarcoma, bacillary angiomatosis, angiosarcoma, non-Hodgkin's lymphoma and metastatic cancers. Final diagnosis can be accurately made by histopathological investigations. Numerous treatment modalities have been defined for PG. But simple surgical excision of the lesion is the usual treatment. ${ }^{6,10}$ Surgical excision with $2 \mathrm{~mm}$ margins at its clinical periphery and full thickness up to the periosteum or to the causative agent is recommended. During the excision, irritant agents such as dental plaque, calculus, foreign bodies, defective restoration and source of trauma should be eliminated. ${ }^{9,11}$

Otherwise electric cauterization, ${ }^{18}$ cryosurgery, ${ }^{19,20}$ sodium tetradecyl sulfate sclerotherapy, ${ }^{21,22}$ monoethanolamine oleate ligation, absolute ethanol injection, ${ }^{23}$ cauterization with silver nitrate, ${ }^{24}$ intralesional steroids, ${ }^{25}$ flash lamp pulsed dye laser, ${ }^{26-30}$ neodymium-doped yttrium aluminium garnet (Nd:YAG) laser, ${ }^{8,31}$ carbon dioxide $\left(\mathrm{CO}_{2}\right)$ laser, ${ }^{32}$ erbium-doped yttrium aluminum garnet (Er:YAG) laser $^{9}$ and diode laser ${ }^{2,3,33,34}$ have also been used by various clinicians to eliminate the lesion.

Although PG does not show infiltrative tendency or malignant transformation potential, the recurrence rate after simple excision is comparatively high (about 16\%); thus in some cases re-excision is required. Recurrence happens following deficient excision, failure to eliminate etiologic factors or re-injury of lesions. Some recurrence can be observed as multiple deep satellite nodules that encircles the site of original lesions (Warner-Wilson Jones syndrome). Also in pregnant females recurrence is common due to the effect of sexual hormones imbalances; therefore treatment should be performed after parturition. It should be underlined that the recurrence rate is much higher in gingival cases than other oral mucosal PG. Recurrence after surgery in extragingival sites is very rare. .,6,10,11 $^{-1}$

This case report describes the use of diode laser in surgical excision of the hard palate's recurrent PG.

\section{Case Report}

A 50-year-old female was referred to the Department of
Oral Surgery at Gazi University, School of Dentistry, complaining about a swelling and growth on the right side of the hard palate, for 4 months. The lesion was painless but caused discomfort and often bled while eating. Patient stated a resembling growth in the same area about two years earlier, which was excised in another institute and biopsy specimen had turned out to be PG.

The patient's medical history and extraoral examination were unexceptional. Intraoral examination revealed a large lobulated sessile mass on the hard palate, which was extending buccally toward the space of the extracted right maxillary first molar. It was reddish pink and covered by a pseudomembrane on some areas. The lesion measured approximately $35 \mathrm{~mm}$ x $30 \mathrm{~mm}$ x $25 \mathrm{~mm}$, with soft to firm consistency and also bled on touch (Figure 1). Periodontal examination revealed inadequate oral hygiene and localized moderate periodontitis in the right maxillary posterior region. According to radiography, there was only horizontal bone loss on the right maxillary posterior teeth due to periodontal disease, but there were no visible abnormalities in the region of the growth (Figure 2). The differential diagnosis comprised peripheral giant cell granuloma, peripheral ossifying fibroma, hemangioma and hyperplastic gingival inflammation. The lesion was provisionally diagnosed as a recurrent PG according to the clinical findings and the previous biopsy report. The patient was asked to give a written informed consent for laser excision of the lesion. Following infiltration local anesthesia(articain 4\% with 1:200.000 epinephrine Ultracaine D-S Forte; Aventis Pharma, Istanbul, Turkey), right maxillary first and second premolar and second molar were extracted, due to moderate periodontitis and bone

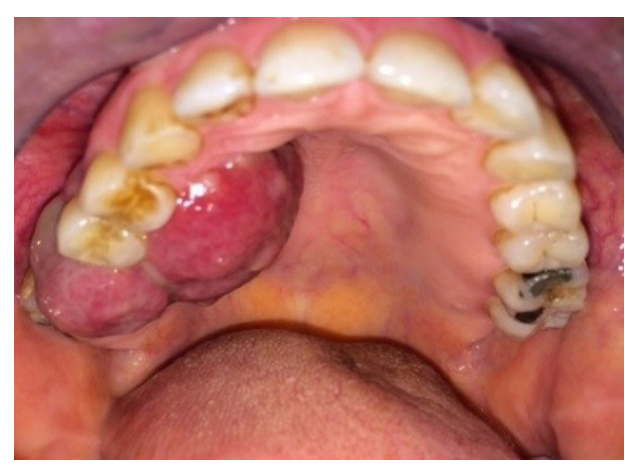

Figure 1. Clinical View at First.

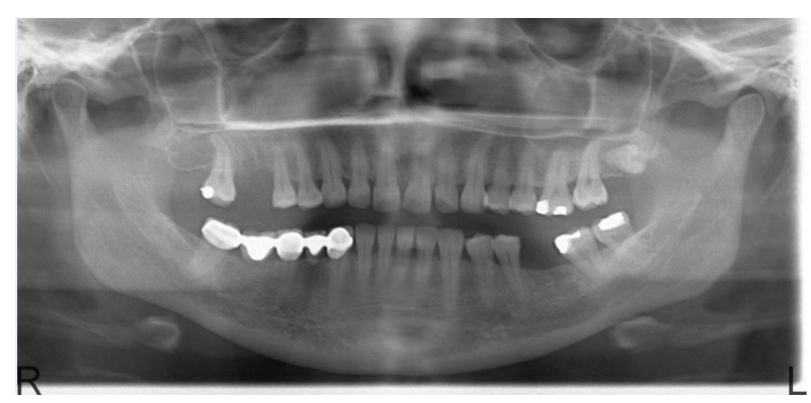

Figure 2. Preoperative Panoramic View of the Patient. 
loss. Then the patient and the whole staff wore protective glasses. A Diode Laser (Doctor Smile Diode Laser, Vicen$\mathrm{za}$, Italy) was used, at $808 \mathrm{~nm}$ wavelength and continuous wave mode, with a power output of $2 \mathrm{~W}$ and a $0.4 \mathrm{~mm}$ diameter fiber optic, for excising the lesion by a trained oral surgery resident. After the laser tip was initiated by rubbing a piece of articulating paper on the fiber to pick up some pigment, the procedure began with outlining the intended incision line. Then the dots were connected to create the designed incision. When the convenient depth was reached, excision was performed by clasping the mass with a forceps, applying traction, and horizontally undermining the tissue. It took 5 minutes to complete the procedure. No sutures were placed after laser surgery and diode laser enabled optimum combination of clean cutting of tissue and hemostasis (Figure 3).

The patient was discharged with necessary post-operative instructions; chlorhexidine mouthwash $(0.12 \%)$ was prescribed, and a follow-up appointment within 7 days was arranged.

The excised sample was stored in $10 \%$ formalin and then sent for histopathological examination. On lower magnification a large ulcerated area covered with fibrin exudate was observed. Otherwise the epithelium was acanthotic, edematous, and invaded by inflammatory cells. Underneath the squamous epithelium, numerous small endothelial lined channels in a lobular structure were seen. A mixed inflammatory cell infiltrate of neutrophils, plasma cells, and lymphocytes was noticed. The lesion had areas with fibrous appearances (Figure 4A). The histopathology confirmed the diagnosis of PG with a positive inferior surgical margin (Figure 4B).

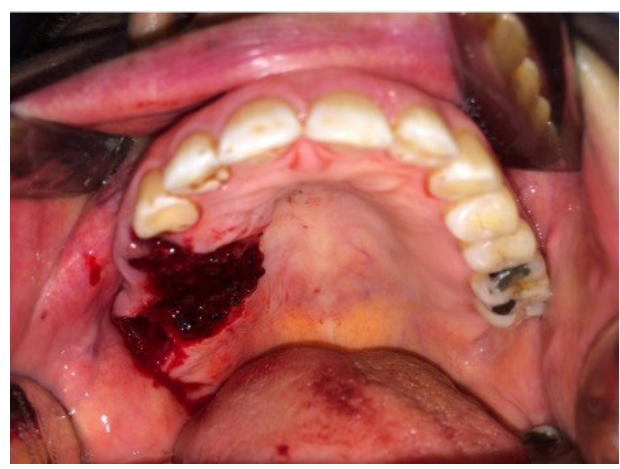

Figure 3. Immediately After Diode Laser Removal.

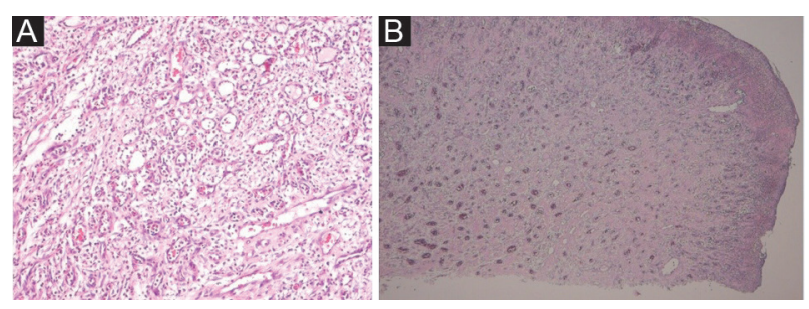

Figure 4. (A) Microscopic View of the Lesion With 200x Magnification. (B) The Histopathological View Showed Positive Inferior Surgical Margin.
At 7 days follow up visit, immediate recurrence of the lesion was observed. On clinical examination small papules were observed in the same region (Figure 5A) and the patient was scheduled for a second visit to excise the lesion; however she failed to keep her appointment and revisited the clinic 3 weeks later. The lesion had conspicuously increased in size (Figure 5A).

Intraoral examination revealed a lobulated oval mass of 15 $\mathrm{mm} \times 10 \mathrm{~mm} \times 2 \mathrm{~mm}$, red in color and soft in consistency, which bled upon probing. As the patient refused scalpel excision, laser surgery was planned again. The lesion was excised with $2 \mathrm{~mm}$ margins at its clinical periphery and to a depth up to the periosteum by the same operator with diode laser (Doctor Smile Diode Laser, Vicenza, Italy), with the same irradiation parameters (Figure 6).

The new sample was sent for histopathological examination and the diagnosis of PG (with negative inferior margin) was reaffirmed. The patient was recalled weekly for 1 month to control for probable recurrence and she was followed up for 14 months, and there has been no recurrence so far (Figure 7 and 8).
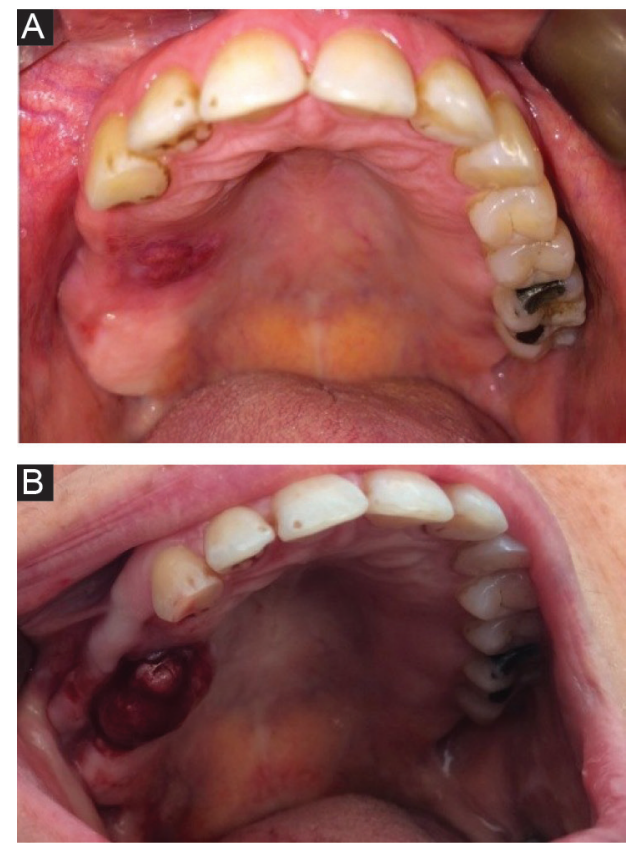

Figure 5. (A) Seven Days After Diode Laser Removal. (B) Three weeks After Diode Laser Removal. The lesion had conspicuously increased in size and readily bled on probing.

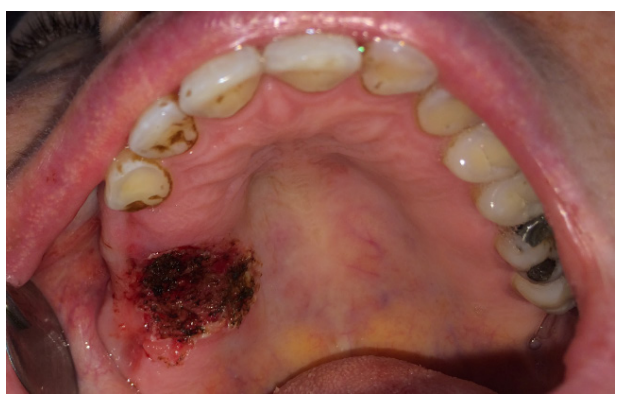

Figure 6. After Immediately Second Laser Surgery. 


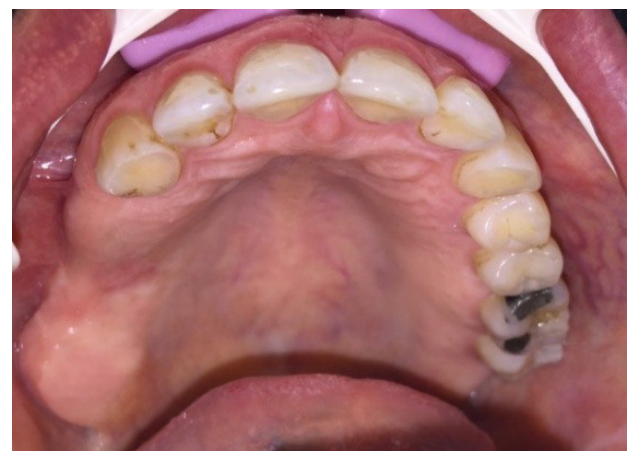

Figure 6. Fourteen Months After Removal of The Lesion.

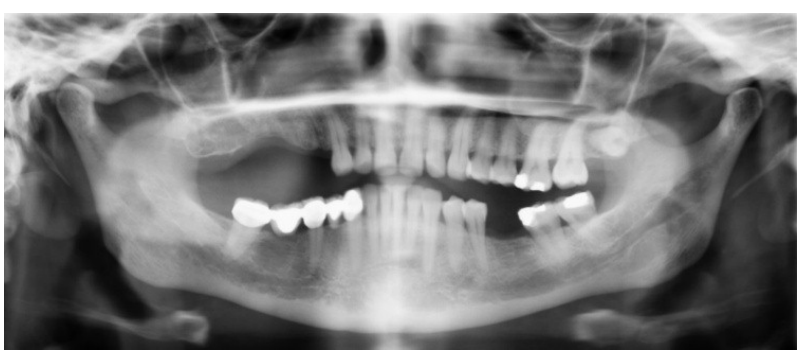

Figure 6. Panoramic View of 14 Months After Removal of the Lesion.

\section{Discussion}

PG is a well-recognized inflammatory hyperplastic oral lesion which comprises about $1.85 \%$ of all oral pathologies, other than caries and gingivitis. ${ }^{35}$ Usually the lesion is neither symptomatic nor painful but minor trauma to the growth can induce significant bleeding. Moreover, PG causes functional problems with mastication, swallowing, speaking and may create esthetic problems. ${ }^{8,10,36}$ In this study the lesion was also painless though it caused discomfort and bleeding while eating, which made the patient go seeking for treatment.

Even though PG is seen in a wide age range, the incidence culminates during the second decade of life, and females seem to be twice more affected. Oral PG occurs most commonly on the gingiva, but can also be encountered on the lips, tongue, buccal mucosa and rarely like this case, it may appear on the hard palate. , $^{3,13,36}$

PG is most commonly treated by surgical excision; but many other treatment modalities, including various types of laser, have also been successfully used., ${ }^{2,3,8,9,27-30,32-34,37} \mathrm{La}-$ ser surgery offers more benefits compared to conventional treatment modalities such as reduced bleeding, instant sterilization, reduced bacteremia, less need for sutures and/or post-surgical dressing, decreased pain and edema during and after the procedure, less wound contraction and minimal scar tissue formation, faster healing process and increased patients acceptance. ${ }^{8,38}$

The effectiveness of the flash lamp pulsed dye laser for the treatment of cutaneous PG have been reported by numerous authors for decades. ${ }^{26-29}$ Meffert et $\mathrm{al}^{30}$ used the flash lamp pulsed dye laser to treat a resolute intraoral mass of granulation tissue, and deduced that a series of treatments with the pulsed dye laser worked well on this lesion.

Powell et $\mathrm{al}^{31}$ reported one of the first uses of $\mathrm{Nd}$ :YAG laser for excision of PG, and noticed decreased risk of bleeding in comparison to other methods along with superior coagulation characteristics; which were the reasons why they chose Nd:YAG laser. Kocaman et $\mathrm{al}^{8}$ proposed the use of Nd:YAG laser in the treatment of PG, due to its effect of decreasing bleeding during operation with a consequent reduction in operating time, promoted postoperative hemostasis and better patient acceptance.

White et $\mathrm{a}^{37}$ used Nd:YAG and $\mathrm{CO}_{2}$ lasers for the excision of benign intraoral lesions including PGs, which was well endured by patients without intraoperative or postoperative side effects.

Fekrazad et $\mathrm{al}^{9}$ preferred Er:YAG laser for excision of a gingival PG and stated that the use of Er:YAG laser can be considered as an effective and safe method for PG excision with minimal invasion. It was also reported that using Er:YAG laser causes less damage on the lesion, hereby the remaining tissue has more pathological value.

Although $\mathrm{CO}_{2}$ and Er:YAG lasers are suitable for cutting due to their higher absorption in water and less penetration, they provide less coagulation than Nd:YAG and diode laser. ${ }^{9}$

Diode laser wavelengths are highly absorbed by pigmented tissue whereas they are poorly absorbed by teeth and bones; therefore soft tissue surgeries can be safely done close to tooth structures. Furthermore diode laser can be used in continuous or gated pulse mode by contact or at an extremely close distance to the tissue, which avoids damage, because it prevents the 'beam escape' in an open field and makes this laser safer than other laser sources. Like Nd:YAG and $\mathrm{CO}_{2}$ lasers, diode lasers have the capability to cut or to vaporize soft tissues. ${ }^{33,39,40}$ In addition, Janda et $\mathrm{l}^{41}$ pointed out that diode laser had low thermal effect on depth of carbonized zones at the surface of the tissue in histological examination. Although in our study the depth of carbonized zone would be negligible due to the lesion's large size, likewise we observed similar findings too.

Rai et $\mathrm{al}^{1}$ used diode laser for the treatment of an intraoral PG with following irradiation parameters: wavelength 808 $\mathrm{nm}( \pm 10)$, output energy $0.1-7.0 \mathrm{~W}$, and input power 300 VA. Without any complication complete healing of the lesion was achieved, and the researchers asserted that diode laser could be a good therapeutic choice for intraoral PGs. Recently several other researchers preferred diode laser when performing excision of PGs., ${ }^{2,3,33,34}$ In our case we chose diode laser because it ensures relatively bloodless surgical field, which is crucial in these hemorrhagic lesions, improves hemostasis and coagulation, and leaves minimal swelling and scarring after surgery.

Several studies have reported that after simple excision, recurrence occurs in up to $16 \%$ of lesions. ${ }^{11,35,42,43}$ Recurrence can be resulted from insufficient excision, failure to eliminate etiologic factors and/or repetitive trauma. Recently, angiopoietin 1, 2 and ephrin b2, agents in other 
vascular tumors such as Bartonella henselae, B. Quintana and human herpesvirus- 8 , have been presumed to have a part in PG recurrence. Viral oncogenes, hormonal influences, microscopic arteriovenous malformation along with inclusion bodies and gene depression in fibroblasts, have also been implied as causes of PG recurrence. In addition, it should be underlined that generally the recurrence rate is much higher in gingival cases than other oral mucosal sites. ${ }^{1,3,44}$

Even though several authors reported no recurrence after laser surgery in the management of PGs, ${ }^{1,2,8,9,32}$ some clinicians still advocate the 'surgical excision' to minimize the risk of recurrence for PGs. ${ }^{3}$ Moreover in the literature, the injection of absolute ethanol, sodium tetradecyl sulfate sclerotherapy and corticosteroids have also been successfully used in recurrent PG cases. ${ }^{23,45,46}$ In this case, insufficient excision and inflammation that result from inadequate oral hygiene could have been the etiology behind the recurrence. However we could not deduce whether diode laser is an effective treatment modality to reduce the recurrence. Further researches are required to investigate the influence of the various types of lasers, laser wavelengths and surgical methods, on the recurrence of PG.

\section{Conclusion}

Although the use of diode laser in the management of intraoral PG is a safe technique with several clinical benefits; clinician should eliminate all the causative irritant and/or source of trauma, and the lesion should be excised with $2 \mathrm{~mm}$ margins at its clinical periphery and to a depth up to the periosteum to prevent the recurrence of PG. Even so, due to its high recurrence rate, long-term follow-up is recommended.

\section{Conflict of Interest}

The author has no conflict of interest to declare.

\section{References}

1. Rai S, Kaur M, Bhatnagar P. Laser: a powerful tool for treatment of pyogenic granuloma. J Cutan Aesthet Surg. 2011;4:144-147. doi:10.4103/0974-2077.85044.

2. Asnaashari M, Mehdipour M, MoradiAbbasabadi F, AzariMarhabi S. Expedited removal of pyogenic granuloma by diode laser in a pediatric patient. J Lasers Med Sci. 2015; 6:40-44.

3. Asnaashari M, Bigom-Taheri J, Mehdipoor M, Bakhshi M, Azari-Marhabi S. Posthaste outgrow of lip pyogenic granuloma after diode laser removal. J Lasers Med Sci. 2014; 5:92-95.

4. Hullihen SP. Case of aneurysm by anastomosis of the superior maxilla. Am J Dent Sc. 1844; 4:160-162.

5. Hartzell MB. Granuloma pyogenicum. J Cutan Dis Syph. 1904; 22:520-525.

6. Jafarzadeh H, Sanatkhani M, Mohtasham N. Oral pyogenic granuloma: a review. J Oral Sci. 2006;48:167-175. doi:10.2334/josnusd.48.167.

7. de Giorgi V, Sestini S, Nardini P, Carli P. A 42-year-old man with a rapidly growing lesion of the soft palate. CMAJ. 2005;173:367. doi:10.1503/cmaj.050242.

8. Kocaman G, Belduz N, Erdogan C, Ozbek E, Sadik E, Kara
C. The use of surgical Nd:YAG laser in an oral pyogenic granuloma: a case report. J Cosmet Laser Ther. 2014;16:197200. doi:10.3109/14764172.2014.910078.

9. Fekrazad R, Nokhbatolfoghahaei H, Khoei F, Kalhori KA. Pyogenic granuloma: surgical treatment with Er:YAG Laser. J Lasers Med Sci. 2014;5:199-205.

10. Gomes SR, Shakir QJ, Thaker PV, Tavadia JK. Pyogenic granuloma of the gingiva: A misnomer? A case report and review of literature. J Indian Soc Periodontol. 2013;17:514519. doi:10.4103/0972-124x.118327.

11. Kamal R, Dahiya P, Puri A. Oral pyogenic granuloma: Various concepts of etiopathogenesis. J Oral Maxillofac Pathol. 2012;16:79-82. doi:10.4103/0973-029x.92978.

12. Regezi JA, Jordan RC, eds. Oral Pathology: Clinical Pathologic Considerations. Philadelphia: WB Saunders; 2003.

13. Esmeili T, Lozada-Nur F, Epstein J. Common benign oral soft tissue masses. Dent Clin North Am. 2005;49:223-240. doi:10.1016/j.cden.2004.07.001.

14. Lebwohl MG, Heyman W, Berth-Jones J, Coulson I, eds. Treatment of Skin Disease: Comprehensive Therapeutic Strategies. Saunders; 2013.

15. Aguilo L. Pyogenic granuloma subsequent to injury of a primary tooth. A case report. Int J Paediatr Dent. 2002;12:438-441. doi:10.1046/j.1365-263x.2000.00388.x.

16. Milano M, Flaitz CM, Bennett J. Pyogenic granuloma associated with aberrant tooth development. Tex Dent J. 2001;118:166-172.

17. Muench MG, Layton S, Wright JM. Pyogenic granuloma associated with a natal tooth: case report. Pediatr Dent. 1992;14:265-267.

18. Alomar MJ. Pyogenic granuloma successfully treated with electric cautarization - case study. J Basic Clin Pharm. 2011; 3:229-234. doi:10.4103/0976-0105.103830.

19. Gupta R, Gupta S. Cryo-therapy in granuloma pyogenicum. Indian J Dermatol Venereol Leprol. 2007;73:141.

20. Ishida CE, Ramos-e-Silva M. Cryosurgery in oral lesions. Int J Dermatol. 1998;37:283-285.

21. Samatha Y, Reddy TH, Jyothirrmai, Ravikiran A, Sankar AJ. Management of oral pyogenic granuloma with sodium tetra decyl sulphate. A case series. N Y State Dent J. 2013; 79:55-57.

22. Deore GD, Gurav AN, Patil R, et al. Sclerotherapy: a novel bloodless approach to treat recurrent oral pyogenic granuloma associated with port-wine stain. Ann Vasc Surg. 2014;28(1564):9-14. doi:10.1016/j.avsg.2014.01.009.

23. Ichimiya $M$, Yoshikawa $Y$, Hamamoto $Y$, Muto $M$. Successful treatment of pyogenic granuloma with injection of absolute ethanol. J Dermatol. 2004;31:342-344.

24. Quitkin HM, Rosenwasser MP, Strauch RJ. The efficacy of silver nitrate cauterization for pyogenic granuloma of the hand. J Hand Surg Am. 2003;28:435-438.

25. Parisi E, Glick PH, Glick M. Recurrent intraoral pyogenic granuloma with satellitosis treated with corticosteroids. Oral Dis. 2006;12:70-72. doi:10.1111/j.1601-0825.2005.01158.x.

26. Tay YK, Weston WL, Morelli JG. Treatment of pyogenic granuloma in children with the flashlamp-pumped pulsed dye laser. Pediatrics. 1997;99:368-370.

27. Goldberg DJ, Sciales CW. Pyogenic granuloma in children. Treatment with the flashlamp-pumped pulsed dye laser. $J$ Dermatol Surg Oncol. 1991;17:960-962.

28. Glass AT, Milgraum S. Flashlamp-pumped pulsed dye laser treatment for pyogenic granuloma. Cutis. 1992;49:351-353. 
29. Gonzalez S, Vibhagool C, Falo LD Jr, Momtaz KT, Grevelink J, Gonzalez E. Treatment of pyogenic granulomas with the $585 \mathrm{~nm}$ pulsed dye laser. J Am Acad Dermatol. 1996;35:428431. doi:10.1016/s0190-9622(96)90610-6.

30. Meffert JJ, Cagna DR, Meffert RM. Treatment of oral granulation tissue with the flashlamp pulsed dye laser. Dermatol Surg. 1998;24:845-848. doi:10.1111/j.1524-4725.1998.tb04261.x.

31. Powell JL, Bailey CL, Coopland AT, Otis CN, Frank JL, Meyer I. Nd:YAG laser excision of a giant gingival pyogenic granuloma of pregnancy. Lasers Surg Med. 1994;14:178183.

32. Lindenmuller IH, Noll P, Mameghani T, Walter C. $\mathrm{CO}_{2}$ laser-assisted treatment of a giant pyogenic granuloma of the gingiva. Int J Dent Hyg. 2010;8:249-252. doi:10.1111/ j.1601-5037.2010.00449.x

33. Akbulut N, Kursun ES, Tumer MK, Kamburoglu K, Gulsen $\mathrm{U}$. Is the $810-\mathrm{nm}$ diode laser the best choice in oral soft tissue therapy? Eur J Dent. 2013;7:207-211. doi:10.4103/13057456.110174.

34. Azma E, Safavi N. Diode laser application in soft tissue oral surgery. J Lasers Med Sci. 2013;4:206-211.

35. Bhaskar SN, Jacoway JR. Pyogenic granuloma--clinical features, incidence, histology, and result of treatment: report of 242 cases. J Oral Surg. 1966;24:391-398.

36. Adusumilli S, Yalamanchili PS, Manthena S. Pyogenic granuloma near the midline of the oral cavity: A series of case reports. J Indian Soc Periodontol. 2014;18:236-239. doi:10.4103/0972-124x.131339.

37. White JM, Chaudhry SI, Kudler JJ, Sekandari N, Schoelch
ML, Silverman S Jr. Nd:YAG and $\mathrm{CO}_{2}$ laser therapy of oral mucosal lesions. J Clin Laser Med Surg. 1998;16:299-304.

38. Strauss RA, Fallon SD. Lasers in contemporary oral and maxillofacial surgery. Dent Clin North Am. 2004;48:861888.

39. Coluzzi DJ. Fundamentals of dental lasers: science and instruments. Dent Clin North Am. 2004;48:751-770.

40. Coleton S. Lasers in surgical periodontics and oral medicine. Dent Clin North Am. 2004;48:937-962.

41. Janda P, Sroka R, Mundweil B, Betz CS, Baumgartner R, Leunig A. Comparison of thermal tissue effects induced by contact application of fiber guided laser systems. Lasers Surg Med. 2003;33:93-101. doi:10.1002/lsm.10199.

42. Kfir Y, Buchner A, Hansen LS. Reactivelesions of the gingiva. A clinicopathological study of 741 cases. J Periodontol. 1980;51:655-661. doi:10.1902/jop.1980.51.11.655.

43. Taira JW, Hill TL, Everett MA. Lobular capillary hemangioma (pyogenic granuloma) with satellitosis. $J$ Am Acad Dermatol. 1992;27:297-300. doi:10.1016/01909622(92)70184-h.

44. Vilmann A, Vilmann P, Vilmann H. Pyogenic granuloma: evaluation of oral conditions. Br J Oral Maxillofac Surg. 1986;24:376-382. doi:10.1016/0266-4356(86)90023-9.

45. Moon SE, Hwang EJ, Cho KH. Treatment of pyogenic granuloma by sodium tetradecyl sulphate sclerotherapy. Arch Dermatol. 2005;141:644-646. doi:10.1001/ archderm.141.5.644.

46. Parisi E, Glick PH, Glick M. Recurrent intraoral pyogenic granuloma with satellitosis treated with corticosteroids. Oral Dis. 2006;12:70-72. doi:10.1111/j.1601-0825.2005.01158.x. 